\title{
Pengaruh Motivasi Dan Disiplin Kerja Terhadap Kinerja Karyawan Hotel Fairuz Di Palangka Raya
}

\author{
Drs. Agau Lenin, $\mathbf{M M}^{\mathbf{1}}$ \\ Dr. Achmad Syamsudin, $\mathbf{M M}^{2}$ \\ Fakultas Ekonomi dan Bisnis \\ Universitas Palangka Raya, Indonesia
}

e-mail: -

\begin{abstract}
Abstrak
Tujuan, - Tujuan penelitian ini adalah untuk mengetahui dan mengetahui pengaruh motivasi dan disiplin kerja terhadap kinerja karyawan pada Hotel Fairuz Palangka Raya.

Desain/Methodologi/Pendekatan - Metode penelitian yang digunakan adalah kualitatif, kuantitatif dengan menggunakan teknik analisis Regresi Linier Berganda. Populasi dan sampel dalam penelitian ini adalah seluruh Kinerja Karyawan di Hotel Fairuz Palangka Raya yang berjumlah 30 orang

Temuan penelitian - Penelitian ini menunjukkan hasil secara parsial (uji-t): a) Motivasi berpengaruh signifikan dan signifikan terhadap Kinerja Karyawan, b) Disiplin Kerja berpengaruh signifikan dan signifikan terhadap Kinerja Karyawan, dan secara simultan hasil penelitian menunjukkan Motivasi Kerja dan Disiplin Kerja berpengaruh signifikan terhadap Kinerja Karyawan dalam penelitian ini $\mathrm{R} 2=0,532$ atau $53,2 \%$.
\end{abstract}

Kata kunci: Motivasi, Disiplin Kerja, dan Kinerja Karyawan

\section{Effect Of Work Motivation And Discipline Toward Employee Performance Fairuz Hotel In Palangka Raya}

\begin{abstract}
Purpose, - The purpose of this study was to determine and to know the effect of work motivation and discipline on employee performance at Fairuz Hotel in Palangka Raya..

Design/methodology/approach - The research method used was qualitative, quantitative by using Multiple Linear Regression analysis techniques. The population and sample in this study were all of the Employees' Performance at Fairuz Hotel in Palangka Raya, totaling 30 people.

Findings - This research shows the results partially (t-test): a) Motivation has significant and significant effect on Employee Performance, b) Work Discipline has a significant and significant effect on Employee Performance, and simultaneously the results of the study show Work Motivation and Discipline have a significant effect on Employee Performance in this study $R 2=0.532$ or $53.2 \%$.
\end{abstract}

Keywords: : Motivation, work discipline, and Employee Performance 


\section{PENDAHULUAN}

Marihot Tua Effendi Hariandja (2009:320) berpendapat bahwa Motivasi adalah sebagai faktor- faktor yang mengarahkan dan mendorong perilaku atau keinginan seseorang untuk melakukan suatu kegiatan yang dinyatakan dalam bentuk usaha yang keras atau lemah. Motivasi karyawan dapat dipengaruhi oleh faktor minat, gaji yang diterima, kebutuhan akan rasa aman, hubungan antar personal dan kesempatan untuk bekerja. Hasil penelitian terdahulu yang dilakukan oleh Muhammad Taufiek Rio Sanjaya (2015) telah membuktikan bahwa variabel disiplin kerja berpengaruh secara positif dan signifikan terhadap kinerja karyawan. Variabel motivasi kerja juga berpengaruh secara positif dan signifikan terhadap kinerja karyawan. Variabel disiplin kerja dan motivasi kerja serentak berpengaruh secara positif dan signifikan terhadap peningkatan kinerja karyawan pada Hotel Ros In Yogyakarta.

Rivai (2010:825) disiplin kerja adalah suatu alat yang digunakan para manajer untuk berkomunikasi dengan karyawan agar mereka bersedia untuk mengubah suatu perilaku serta sebagai suatu upaya untuk meningkatkan kesadaran dan kesediaan seseorang mentaati semua peraturan perusahaan atau organisasi dan norma-norma sosial yang berlaku. Kinerja karyawan (prestasi kerja) adalah hasil kerja secara kualitas dan kuantitas yang dicapai oleh seorang pegawai dalam melaksanakan fungsinya sesuai dengan tanggung jawab yang diberikan kepadanya. Hasil penelitian terdahulu yang dilakukan oleh Ridha Canggih Pristian (2011) telah membuktikan bahwa motivasi dan disiplin secara bersama-sama memiliki pengaruh positif dan signifikan terhadap kinerja pegawai Dinas Kehutanan dan Perkebunan Kabupaten Jepara. Secara simultan besarnya kontribusi yang diberikan oleh variabel motivasi dan disiplin terhadap kinerja pegawai.

Berdasarkan penelitian yang telah dilakukan peneliti dengan menggunakan metode wawancara terhadap beberapa karyawan telah ditemukan bahwa motivasi dan disiplin kerja pada Hotel Fairuz di Palangka Raya pada dasarnya sudah termasuk baik atau terkendali, akan tetapi masih ditemukan adanya presentasi fluktuatif yang mengatakan bahwa masih banyak karyawan yang datang terlambat masuk kerja dan tidak masuk kerja tanpa adanya surat keterangan. Serta adanya keluhan yang diberikan oleh beberapa tamu yang menginap di hotel Fairuz dengan mengatakan bahwa adanya keterlambatan waktu karyawan dalam mempersiapkan kamar dan membersihkan kamar.

Berdasarkan tinjauan pustaka, maka disusunlah kerangka pemikiran sebagai sebuah model penelitian untuk menjelaskan bagaimana Kinerja Karyawan ditentukan oleh Pengaruh Motivasi dan Disiplin Kerja seperti pada gambar berikut:

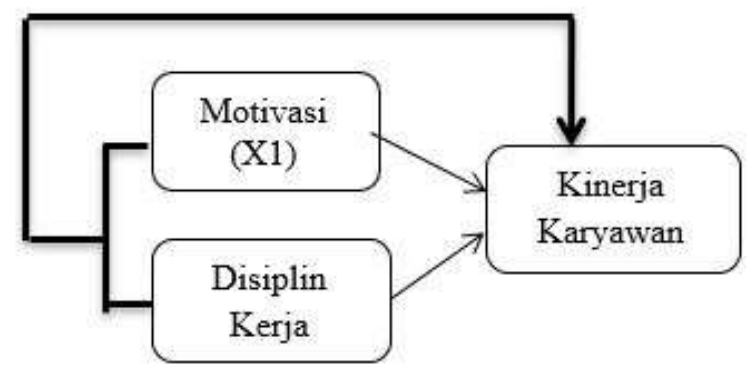

Gambar 1. Kerangka Pemikiran

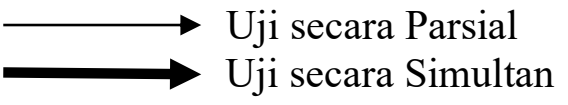




\section{Motivasi (X1):}

A. A. Prabu Mangkunegara (2009:93), berpendapat bahwa Motivasi adalah kondisi yang menggerakan pegawai agar mampu mencapai tujuan dari motifnya.

\section{Disiplin Kerja (X2):}

Rivai (2010:825) disiplin kerja adalah suatu alat yang digunakan para manajer untuk berkomunikasi dengan karyawan agar mereka bersedia untuk mengubah suatu perilaku serta sebagai suatu upaya untuk meningkatkan kesadaran dan kesediaan seseorang mentaati semua peraturan perusahaan atau organisasi dan norma-norma sosial yang berlaku.

\section{Kinerja Karyawan (Y):}

Mangkuprawira (2007:22) kinerja yaitu hasil proses pekerjaan tertentu secara terencana pada waktu dan tempat dari karyawan serta organisasi bersangkutan.

Suatu variabel dapat mempengaruhi variabel yang lain, sehingga ada hubungan sebab akibat dimana variabel bebas (independent variabel) adalah Motivasi (X1) dan Disiplin Kerja (X2), Sedangkan variabel terikat (dependent variabel) adalah Kinerja Karyawan (Y).

\section{METODE PENELITIAN}

Jenis penelitian yang digunakan adalah penelitian eksplantasi yang bermaksud menjelaskan kedudukan variabel-variabel yang diteliti dengan variabel lain (Siregar, 2012). Ukuran sampel menggunakan rumus Slovin dalam (Husein Umar, 2010) adalah sebagai berikut:

Keterangan:

$$
\mathrm{n}=\frac{N}{1+N e^{2}}
$$

$\mathrm{n} \quad=$ besar sampel

$\mathrm{N}=$ besar Populasi

e = batas kesalahan yang diperbolehkan sebanyak 5\%

Jenis data yang digunakan dalam penelitian ini, adalah:

1. Data kualitatif adalah data yang tidak bisa diukur atau dihitung secara langsung, hanya bisa diperoleh melalui variabel indikator dengan menggunakan instrumen pengumpulan data dengan kuesioner.

2. Data kuantitatif adalah data yang berbentuk angka/besaran tertentu yang sifatnya pasti atau data kualitatif yang diangkakan.

Skala Likert digunakan untuk mengukur sikap, pendapat, dan persepsi seorang atau kelompok orang tentang fenomena sosial (Sugiyono,2013). Dengan Skala Likert, maka variabel yang akan diukur dijabarkan menjadi indikator variabel. Kemudian indikator tersebut dijadikan sebagai titik tolak untuk menyusun item-item instrumen yang dapat berupa pertanyaan atau pernyataan. Pada penelitian ini Skala Liker digunakan untuk mengetahui bagaimana sikap, pendapat, dan persepsi responden terhadap variabel motivasi dan disiplin kerja terhadap kinerja karyawan Hotel Fairuz Palangka Raya. Responden diminta menunjukkan persetujuan atau ketidaksetujuannya pada setiap pertanyaan yang diberi jarak atau interval 5 poin (Sugiono, 2004). 
Adapun jawaban dari pertanyaan/pernyataan adalah sebagai berikut:

Tabel 1. Tabel Skala Likert

\begin{tabular}{|ll|c|}
\hline Keterangan & Bobot Nilai \\
\hline Sangat Setuju & 5 \\
\hline Setuju & (S) & 4 \\
\hline Netral & (N) & 3 \\
\hline Tidak Setuju & (TS) & 2 \\
\hline Sangat Tidak Setuju & (STS) & 1 \\
\hline
\end{tabular}

Sebagai bahan interprestasi hasil analisis deskriptif maka kategori sangat setuju sampai sangat tidak setuju menggunakan interval atau ruang skala, dengan rumus:

$$
\text { Interval }=\frac{\text { Nilai } \text { Tertinggi }- \text { Nilai terendah }}{\text { Jumlah } \text { kelas atau } \text { kelompok }}=\frac{(5-1)}{5}=0,8 \quad(\text { Sugiyono, 2010) }
$$

Tabel 2. Penentuan Nilai Ukur pada Kuesioner

\begin{tabular}{|ccccc|}
\hline Kelompok & $\begin{array}{c}\text { Batas } \\
\text { Bawah }\end{array}$ & Interval & $\begin{array}{c}\text { Batas } \\
\text { Atas }\end{array}$ & Keterangan \\
\hline 1 & 1,00 & 0,80 & 1,79 & Sangat tidak setuju \\
\hline 2 & 1,80 & 0,80 & 2,59 & Tidak Setuju \\
\hline 3 & 2,60 & 0,80 & 3,39 & Cukup Setuju \\
\hline 4 & 3,40 & 0,80 & 4,19 & Setuju \\
\hline 5 & 4,20 & 0,80 & 5,00 & Sangat Setuju \\
\hline
\end{tabular}

Berdasarkan nilai Tabel 3.3, maka nilai yang ditentukan dapat dikategorikan sebagai berikut: Nilai antara $1,00 \mathrm{~s} / \mathrm{d} 1,79=$ Sangat Tidak Setujuu

Nilai antara 1,80 s/d 2,59= Tidak Setuju

Nilai antara 2,60 s/d 3,39= Cukup Setuju

Nilai antara $3,40 \mathrm{~s} / \mathrm{d} 4,19=$ Setuju

Nilai antara 4,20 s/d 5,00 = Sangat Setuju

\section{HASIL PENELITIAN}

Tabel 3. Penilaian Responden Mengenai Variabel Kinerja Karyawan (Y)

\begin{tabular}{|c|c|c|c|c|c|c|c|c|c|}
\hline \multirow[b]{2}{*}{$\begin{array}{l}\text { Nomor } \\
\text { Item }\end{array}$} & \multirow[b]{2}{*}{ Pernyataan } & \multicolumn{6}{|c|}{ Skor Jawaban } & \multicolumn{2}{|c|}{ Mean } \\
\hline & & SS & $\mathrm{S}$ & $\mathrm{N}$ & $\mathrm{TS}$ & STS & $\mathrm{N}$ & Item & $\begin{array}{l}\text { Rata- } \\
\text { rata }\end{array}$ \\
\hline \multicolumn{10}{|c|}{ Kinerja Karyawan } \\
\hline & $\begin{array}{l}\text { Bekerja dengan hasil yang } \\
\text { baik. }\end{array}$ & & & & & & & & \\
\hline & $\begin{array}{l}\text { Mampu memenuhi target } \\
\text { yang dibebankan. }\end{array}$ & & & & & & 30 & 3,77 & \\
\hline & $\begin{array}{l}\text { Mampu memenuhi target } \\
\text { yang dibebankan sebelum } \\
\text { batas waktunya. }\end{array}$ & & & & & & 30 & 3,8 & \\
\hline & $\begin{array}{l}\text { Mampu bekerja dengan tepat } \\
\text { waktu. }\end{array}$ & & & & & & 30 & 3,7 & \\
\hline
\end{tabular}




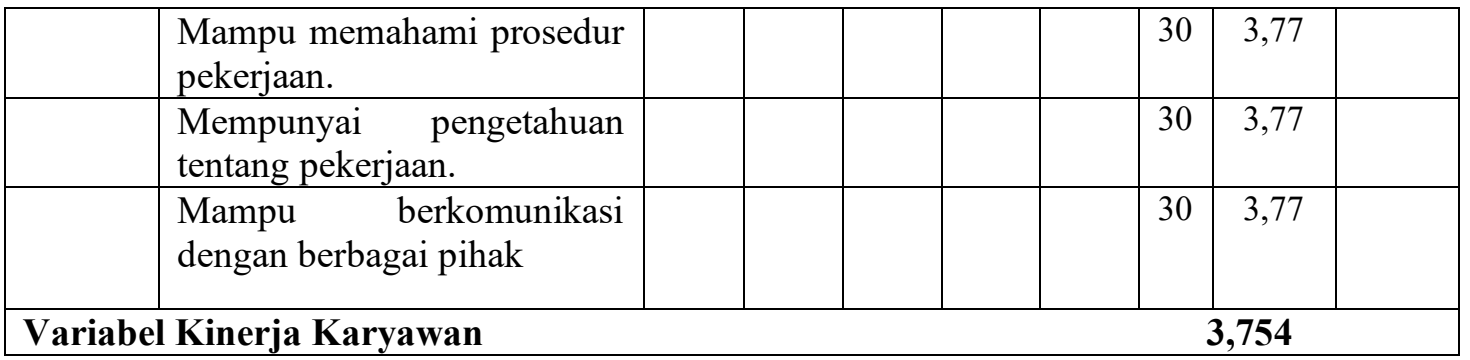

Sumber: Data olahan

Hasil jawaban responden sebanyak 30 orang Pegawai terhadap variabel Kinerja Karyawan (Y) yang diukur:

Variabel Y.1 menunjukan hasil jawaban dengan presentase terbesar pada kategori Setuju (17\%), sehingga rata-rata mean 3,7 dengan kategori Baik. Artinya 74\% karyawan bekerja dengan hasil yang baik. Variabel Y2 menunjukan hasil jawaban dengan presentase terbesar pada kategori Setuju (17\%), sehingga rata-rata mean 3,77 dengan kategori Baik. Artinya 75,4\% Karyawan mampu memenuhi target yang dibebankan. Variabel Y3 menunjukan hasil jawaban dengan presentase terbesar pada kategori Setuju (16\%), sehingga rata-rata mean 3,8 dengan kategori Baik. Artinya 74\% karyawan mampu memenuhi target yang dibebankan sebelum batas waktunya. Variabel Y4 menunjukan hasil jawaban dengan presentase terbesar pada kategori Setuju (18\%), sehingga rata-rata mean 3,7 dengan kategori Baik. Artinya 74\% karyawan mampu bekerja dengan tepat waktu. Variabel Y5 menunjukan hasil jawaban dengan presentase terbesar pada kategori Setuju (17\%), sehingga rata-rata mean 3,77 dengan kategori Baik. Artinya 75,4\% karyawan mampu memahami prosedur pekerjaan. Variabel Y6 menunjukan hasil jawaban dengan presentase terbesar pada kategori Setuju (17\%), sehingga rata-rata mean 3,77 dengan kategori Baik. Artinya 75,4\% karyawan mampu memahami prosedur pekerjaan.

Variabel Y7 menunjukan hasil jawaban dengan presentase terbesar pada kategori Setuju (17\%), sehingga rata-rata mean 3,77 dengan kategori Baik. Artinya 75,4\% karyawan mampu memahami prosedur pekerjaan. Variabel Kinerja Karyawan (Y) menunjukkan rata-rata mean 3,754 dengan kategori baik. Artinya variabel Kinerja Karyawan sangat berpengaruh terhadap karyawan Hotel Fairuz dengan capaian sebesar 75,8\%.

Dalam penelitian ini uji validitas menggunakan program SPSS versi 23. Uji validitas ini menggunakan Pearson Corelation, yaitu dengan mengkorelasikan skor item dengan skor total item. Kriteria pengujian adalah sebagai berikut:

Berdasarkan hasil penelitian diperoleh nilai Tolerence untuk variabel Motivasi dan Disiplin Kerja yaitu sebesar 0,990, kedua nilai Tolerence dari variabel diatas $>0,10$ dan nilai VIF untuk variabel Motivasi dan Disiplin Kerja yaitu sebesar 1,010. Kedua nilai VIF dari variabel diatas $<10,00$ yang berarti bahwa model regresi tidak mengandung multikolinieritas.

Analisis regresi linier berganda digunakan untuk menduga berapa besar pengaruh suatu variabel (independent) terhadap variabel (dependent) dalam penelitian ini. Berikut hasil analisis regresi linier berganda:

persamaan regresi sebagai berikut:

$\mathrm{Y}=17,823+0,414 \mathrm{X}_{1}+0,191 \mathrm{X}_{2}$

Persamaan regresi liner berganda diatas, dapat diinterprestasikan sebagai berikut:

a) Koefisien regresi Motivasi $\left(\mathrm{X}_{1}\right)=0,414$ artinya pada saat Disiplin Kerja $\mathrm{X}_{2}$ $=0$ (konstan) maka besarnya pengaruh variabel Motivasi terhadap Kinerja Karyawn adalah 41,4\% dengan kata lain jika variabel Motivasi meningkat sebesar satu persen akan meningkatkan nilai Kinerja Karyawan sebesar 0,414 atau 41,4\%. 
b) Koefisien regresi Disiplin Kerja $\left(\mathrm{X}_{2}\right)=0,191$ artinya pada saat Motivasi $\mathrm{X}_{1}=0$ maka besarnya pengaruh variabel Disiplin Kerja terhadap Kinerja Karyawan adalah 19,1\% dengan kata lain jika Disiplin Kerja meningkat sebesar satu persen Kinerja Karyawan akan meningkat sebesar 0,191 atau 19,1\%.

\section{Pembahasan Hasil Penelitian}

Pembahasan penelitian bertujuan untuk memberikan penjelasan hasil penelitian baik hasil deskriptif maupun hasil pengujian hipotesis. Analisis deskriptif dilakukan untuk melihat frekuensi terhadap setiap skor alternatif jawaban kuesioner, sehingga diperoleh skor rata-rata jawaban responden. Berikut hasil perhitungan hasil rata-rata variabel.

Tabel 4. Skor Rata-Rata Perhitungan Variabel Penelitian

\begin{tabular}{|l|l|l|l|}
\hline No. & Variabel & Skor Rata-rata & Kategori \\
\hline 1. & Motivasi $\mathrm{X}_{1}$ & 3,800 & Netral \\
\hline 2. & Disiplin Kerja $\mathrm{X}_{2}$ & 3,965 & Netral \\
\hline 3. & Kinerja Karyawan $\mathrm{Y}$ & 3,754 & Netral \\
\hline
\end{tabular}

Sumber: Data Primer diolah (2019)

Hasil penelitian mengenai variabel Motivasi Dan Disiplin Kerja Terhadap Kinerja Karyawan Hotel Fairuz Palangka Raya.

\section{Uji Validitas}

Dalam penelitian ini uji validitas menggunakan program SPSS versi 23. Uji validitas ini menggunakan Pearson Corelation, yaitu dengan mengkorelasikan skor item dengan skor total item. Kriteria pengujian adalah sebagai berikut:

Jika $r_{\text {hitung }}>r_{\text {tabel }}(n=30)=0.349$ (uji 2 sisi dengan sig 0,05$)$ maka kuesioner dinyatakan valid. Jika $r_{\text {hitung }}<r_{\text {tabel }}(n=30)=0,349$ (uji 2 sisi dengan sig 0,05$)$ maka kuesioner dinyatakan tidak valid.

Hasil Uji Validitas Instrumen Penelitian

\begin{tabular}{|l|l|c|c|c|}
\hline No. & Item & $\begin{array}{c}\text { Pearson Corelation } \\
\text { (Skor total }{ }^{\text {hitung }} \text { ) }\end{array}$ & $\mathrm{r}_{\text {tabel 5\% }}(\mathrm{n}=30)$ & Keterangan \\
\hline 1 & $\mathrm{X} 1.1$ & 0,838 & 0,349 & Valid \\
\hline 2 & $\mathrm{X} 1.2$ & 0,824 & 0,349 & Valid \\
\hline 3 & $\mathrm{X} 1.3$ & 0,953 & 0,349 & Valid \\
\hline 4 & $\mathrm{X} 1.4$ & 0,953 & 0,349 & Valid \\
\hline 5 & $\mathrm{X} 1.5$ & 0,838 & 0,349 & Valid \\
\hline 6 & $\mathrm{X} 1.6$ & 0,824 & 0,349 & Valid \\
\hline 7 & $\mathrm{X} 1.7$ & 0,985 & 0,349 & Valid \\
\hline 8 & $\mathrm{X} 2.1$ & 0,996 & 0,349 & Valid \\
\hline 9 & $\mathrm{X} 2.2$ & 0,985 & 0,349 & Valid \\
\hline 10 & $\mathrm{X} 2.3$ & 0,911 & 0,349 & Valid \\
\hline 11 & $\mathrm{X} 2.4$ & 0,973 & 0,349 & Valid \\
\hline 12 & $\mathrm{X} 2.5$ & 0,975 & 0,349 & Valid \\
\hline 13 & $\mathrm{X} 2.6$ & 0,996 & 0,349 & Valid \\
\hline 14 & $\mathrm{X} 2.7$ & 0,996 & 0,349 & Valid \\
\hline 15 & $\mathrm{X} 2.8$ & 0,975 & 0,349 & Valid \\
\hline 16 & $\mathrm{X} 2.9$ & 0,996 & & \\
\hline
\end{tabular}




\begin{tabular}{|l|l|l|l|l|}
\hline 17 & X2.10 & 0,973 & 0,349 & Valid \\
\hline 18 & Y1 & 0,990 & 0,349 & Valid \\
\hline 19 & Y2 & 0,957 & 0,349 & Valid \\
\hline 20 & Y3 & 0,947 & 0,349 & Valid \\
\hline 21 & Y4 & 0,853 & 0,349 & Valid \\
\hline 22 & Y5 & 0,957 & 0,349 & Valid \\
\hline 23 & Y6 & 0,957 & 0,349 & Valid \\
\hline 24 & Y7 & 0,970 & 0,349 & Valid \\
\hline
\end{tabular}

Sumber: Lampiran IV

Berdasarkan hasil uji validitas terhadap item-item pertanyaan pada tabel 4.6 diatas dapat dilihat korelasi dari tiap-tiap item menunjukkan bahwa $r_{\text {hitung }}>r_{\text {tabel }}(n=30) 0,349$. Dengan demikian dapat disimpulkan bahwa pernyataan dikatakan valid.

\section{Uji Multikolinieritas}

Uji Multikolinieritas digunakan untuk menguji apakah antara variabel bebas memiliki hubungan yang sempurna atau tidak, syarat diterimanya model regresi berganda apabila antara variabel bebas tidak mengandung korelasi yang sempurna. Pengujian multikolinieritas dapat dilihat dari nilai variance inflance factor (VIF) berdasarkan hasil output SPSS. Apabila nilai VIF $<10,00$ dan mendekati 1 dapat disimpulkan bahwa asumsi adanya multikolinieritas ditolak.

Tabel 5. Hasil Uji Multikolinieritas

Coefficients $^{\mathrm{a}}$

\begin{tabular}{|c|c|c|c|c|c|c|c|}
\hline \multirow[b]{2}{*}{ Model } & \multicolumn{2}{|c|}{$\begin{array}{l}\text { Unstandardized } \\
\text { Coefficients }\end{array}$} & \multirow{2}{*}{$\begin{array}{c}\text { Standardized } \\
\text { Coefficients } \\
\text { Beta }\end{array}$} & \multirow[b]{2}{*}{$t$} & \multirow[b]{2}{*}{ Sig. } & \multicolumn{2}{|c|}{$\begin{array}{l}\text { Collinearity } \\
\text { Statistics }\end{array}$} \\
\hline & $B$ & Std. Error & & & & Tolerance & VIF \\
\hline $1 \quad$ (Constant) & 17,823 & 2,762 & & 6,453 & ,000 & & \\
\hline Motivasi & ,414 & , 100 & ,551 & 4,163 &, 000 & ,990 & 1,010 \\
\hline Disiplin_Kerja & ,191 & ,059 & ,426 & 3,217 & ,003 & ,990 & 1,010 \\
\hline
\end{tabular}

a. Dependent Variable: Kinerja_Karyawan

Sumber: Lampiran V

Berdasarkan hasil penelitian diperoleh nilai Tolerence untuk variabel Motivasi dan Disiplin Kerja yaitu sebesar 0,990, kedua nilai Tolerence dari variabel diatas $>0,10$ dan nilai VIF untuk variabel Motivasi dan Disiplin Kerja yaitu sebesar 1,010. Kedua nilai VIF dari variabel diatas $<10,00$ yang berarti bahwa model regresi tidak mengandung multikolinieritas.

\section{Uji t}

Pengujian hipotesis dilakukan dengan uji parsial (uji t). Uji t digunakan untuk mengetahui pengaruh variabel bebas dan variabel terikat secara parsial.

Merumuskan hipotesis

$\mathrm{H}_{0}: \mathrm{b}_{1}=0$, artinya tidak terdapat pengaruh yang signifikan dari variabel bebas/independent Motivasi $\left(\mathrm{X}_{1}\right)$ dan Disiplin Kerja $\left(\mathrm{X}_{2}\right)$ terhadap variabel terikat/dependent Kinerja Karyawan (Y).

$\mathrm{H}_{\mathrm{a}}: \mathrm{b}_{1} \neq 0$, artinya terdapat pengaruh yang signifikan dari variabel bebas/independent Motivasi $\left(\mathrm{X}_{1}\right)$ dan Disiplin Kerja $\left(\mathrm{X}_{2}\right)$ terhadap variabel terikat/dependent Kinerja Karyawan (Y).

Menentukan thitung

Dari hasil perhitungan SPSS versi 23 diperoleh angka $t_{\text {hitung }} X_{1}$ sebesar 4,163 dan $t_{\text {hitung }} X_{2}$ sebesar 3,217. 
Menentukan $t_{\text {tabel }}$

Dengan menetapkan tingkat kepercayaan $(\alpha)$ dan derajat bebas $(\mathrm{df})=(n-k-1)$. Taraf signifikan 0,05 dan derajat kebebasan (df) dengan ketentuan $\mathrm{df}=30-3-1=26$ dari ketentuan tersebut diperoleh $\mathrm{t}_{\text {tabel }}=1,706$.

Membuat keputusan hipotesis dengan membandingkan $t_{\text {hitung }}$ dengan $t_{\text {tabel }}(\alpha)$ yaitu:

Jika $\mathrm{t}_{\text {hitung }}<\mathrm{t}_{\text {tabel }}$ maka $\mathrm{H}_{0}$ diterima $\mathrm{H}_{\mathrm{a}}$ ditolak, sehingga tidak terdapat pengaruh yang signifikan antara variabel bebas dan variabel terikat.

Jika $t_{\text {hitung }}>\mathrm{t}_{\text {tabel }}$ maka $\mathrm{H}_{0}$ ditolak $\mathrm{H}_{\mathrm{a}}$ diterima sehingga terdapat pengaruh yang signifikan antara variabel bebas dan variabel terikat.

Karena nilai thitung $X_{1}(4,163)>t_{\text {tabel }}(1,706)$ dan nilai thitung $X_{2}(3,217)>t_{\text {tabel }}(1,706)$. Karena nilai $t_{\text {hitung }} \mathrm{X}_{1}(4,163)>\mathrm{t}_{\text {tabel }}(1,706)$, maka $\mathrm{H}_{0}$ ditolak $\mathrm{H}_{\mathrm{a}}$ diterima sehingga terdapat pengaruh yang signifikan antara variabel bebas Motivasi $\left(\mathrm{X}_{1}\right)$ dan variabel terikat Kinerja Karyawan $(Y)$, sedangkan karena nilai thitung $\mathrm{X}_{2}(3,217)>\mathrm{t}_{\text {tabel }}(1,706)$ maka $\mathrm{H}_{0}$ ditolak $\mathrm{H}_{\mathrm{a}}$ diterima sehingga terdapat pengaruh yang signifikan antara variabel bebas Disiplin Kerja $\left(\mathrm{X}_{2}\right)$ dan variabel terikat Kinerja Karyawan (Y).

\section{KESIMPULAN DAN SARAN}

Hasil penelitian menunjukan bahwa presepsi rata-rata dari responden terhadap variabel Motivasi $\left(\mathrm{X}_{1}\right)$ memiliki kategori baik. Artinya variabel Motivasi sangat berpengaruh terhadap Kinerja Karyawan. Hasil analisis menunjukan variabel Motivasi $\left(\mathrm{X}_{1}\right)$ berpengaruh positif dan signifikan terhadap Kinerja Karyawan Hotel Fairuz Palangka Raya. Hasil penelitian menunjukan bahwa presepsi rata-rata dari responden terhadap variabel Disiplin Kerja $\left(\mathrm{X}_{2}\right)$ memiliki kategori baik. Artinya variabel Disiplin Kerja sangat berpengaruh terhadap Kinerja Karyawan. Hasil analisis menunjukkan bahwa variabel Disiplin Kerja $\left(\mathrm{X}_{2}\right)$ berpengaruh positif dan signifikan terhadap Kinerja Karyawan Hotel Firuz Palangka Raya. Hasil penelitian menunjukan bahwa presepsi rata-rata dari responden terhadap variabel Kinerja Karyawan dengan kategori baik. Artinya variabel Kinerja Karyawan sangat berpengaruh terhadap Kinerja Karyawan Hotel Fairuz Palangka Raya. Hasil analisis menunjukan bahwa variabel Motivasi $\left(\mathrm{X}_{1}\right)$ dan Disiplin Kerja $\left(\mathrm{X}_{2}\right)$ secara simultan sangat berpengaruh terhadap variabel Kinerja Karyawan Hotel Fairuz Palangka Raya.

\section{Saran-Saran}

Bagi Pihak Hotel Fairuz Palangka Raya

Diharapkan penelitian ini dapat dijadikan pertimbangan untuk mengatasi masalah yang terjadi pada karyawan Hotel Fairuz Palangka Raya:

- Untuk meningkatkan motivasi kerja para karyawan dengan memperhatikan pemberian gaji yang sesuai dengan pekerjaan yang diberikan sesuai dengan keahlian;

- Hak pemberian tunjangan karyawan, dan hubungan terhadap atasan berjalan dengan baik hal ini akan mendorong terciptanya disiplin kerja dan motivasi kerja, sehingga dapat meningkatkan kinerja para karyawan secara maksimal.

Bagi peneliti selanjutnya, yang tertarik melakukan penelitian tentang variabel Motivasi dan Disiplin Kerja terhadap Kinerja Karyawan diharapkan untuk mengobservasi dan mengekplorasi lebih jauh mengenai permasalahan-permasalahan yang ada sehingga penelitian tentang variabel Motivasi dan Disiplin Kerja Terhadap Kinerja Karyawan dapat terus berkembang dan memudahkan untuk pembaca dalam mengerti maksud dari permasalahan yang ada. 


\section{DAFTAR PUSTAKA}

Arikunto. (2006). Metodelogi Penelitian. Semarang. Penerbit Universitas Diponegoro. Ambar Teguh (2003). Manajemen Sumber Daya Manusia. Graha Ilmu:Yogyakarta. Anwar Prabu Mangkunegara (2001). Manajemen Sumber Daya Perusahaan, PT. Remaja Rosdakarya, Bandung.

A. A. Prabu Mangkunegara (2009). Manajemen Sumber Daya Perusahaan, PT. Remaja Rosdakarya, Bandung.

Erga Adnan Ramatha (2015) Skripsi tentang "Pengaruh kedisiplinan kerja dan motivasi terhadap kinerja pegawai (Studi Kasus pada SMP Negeri 3 Surakarta).

Ghozali. (2006). Metode Penelitian. Jakarta. Penerbit PT. Remaja Rosdakarya. Bandung.

Ghozali. (2012) . Metode Penelitian. Jakarta. Penerbit Suci Pres

Handoko, T. Hani. (2006). Manajemen Personalia dan Sumber Daya Manusia. B.P.F.E UGM, Yogyakarta.

Hasibuan (2000). Manajemen Sumber Daya Manusia. PT. Bumi Aksara, Jakarta.

Hasibuan (2006). Manajemen Sumber Daya Manusia. Jakarta: CV. Haji Masagung.

Hasibuan (2007). Manajemen Sumber Daya Manusia. Jakarta: CV. Haji Masagung.

Harlie, M. (2012). "Pengaruh Disiplin kerja, Motivasi dan Pengembangan Karier Terhadap Kinerja Pegawai Negeri Sipil Pada Pemerintah Kabupaten Tabalong di Tanjung Kalimantan Selatan”. Jurnal Manajemen dan Akuntansi.Vol. 11 No. 2, Oktober 2010; 117-124.

Hamzah B. Uno. (2009). Manajemen Sumber Daya Manusia. Jakarta: CV. Haji Masagung.

Johar. (2005). Aplikasi Excel dalam Aspek Kuantitatif Manajemen Sumber Daya Manusia, edisi pertama, Jakarta : PT. Elex Media Komputindo.

Kadarisman. (2012). Manajemen Pengembangan Sumber Daya Manusia. Rajawali Pers, Jakarta

Kadarsiman (2012). Manajemen Pengembangan Sumber Daya Manusia. Rajawali Pers, Jakarta

Mangkunegara. (2007). Manajemen Sumber Daya Perusahaan, PT. Remaja Rosdakarya. Bandung.

Marihot Tua Effendi Hariandja. (2009). Manajemen Sumber Daya Manusia.Jakarta: PT.Grasindo.

Muhammad Taufiek Rio Sanjaya. (2015) Skripsi tentang "Pengaruh disiplin kerja dan motivasi kerja terhadap kinerja karyawan pada Hotel Ros In Yogyakarta".

Malayu Hasibuan. (2013). Manajemen Sumber Daya Manusia. Jakarta : CV. Haji Masagung. Riduwan. (2003). Metode Penelitian. Jakarta. Penerbit Suci Pres.

Robbins (2008). Manejemen Sumber Daya Manusia. Ghalia Indonesia: Bogor.

Ridha Canggih Pristian (2011) Skripsi tentang "Pengaruh motivasi dan disiplin terhadap kinerja pegawai pada dinas kehutanan dan perkebunan kabupaten Jepara.

Rivai. (2011). Manajemen Sumber Daya Manusia untuk Perusahaan.Jakarta: PT. Raja Grafindo Persada.

Sutrisno, Edy. (2013). Manajemen Sumber Daya Manusia, Edisi Pertama, Jakarta : Kencana. Siregar. (2012). Metodelogi Penelitian. Jakarta. Penerbit Erlangga.

Sutrisno (2016) Sutrisno, Edy. 2013. Manajemen Sumber Daya Manusia, Edisi Pertama, Jakarta : Kencana.

Sofyan Sieregar. (2013). Metodelogi Penelitian. Jakarta. Penerbit Erlangga.

Safaniah. (2001). Metodelogi Penelitian. Jakarta. Penerbit Erlangga.

Sugiyono. (2004). Metode Penelitian. Jakarta. Penerbit Suci Pres.

Sugiyono. (2011). Statistik untuk Pendidikan. Bandung. Penerbit Alfabeta, 
Sugiyono. (2015). Metode Penelitian. Jakarta. Penerbit Suci Pres.

Suyadi. (1997). Manajemen Sumber Daya Manusia untuk Perusahaan.Jakarta: PT. Raja Grafindo Persada.

Thoha, (2005). Perilaku Organisasi: Konsep Dasar dan Aplikasinya. Jakarta: Raja Grafindo Persada

Uno, Hamzah B. (2009). Teori motivasi dan Pengukurannya (Analisis di Bidang Pendidikan).Jakarta : Bumi Aksara 